\title{
Six Year Trend Analysis of Malaria Prevalence in Bati District, Northeastern Ethiopia: A Retrospective Study
}

Chala Daba ( $\sim$ chaladaba293@gmail.com )

Bule Hora University https://orcid.org/0000-0002-4906-9610

Edosa Kebede

Ambo University

Amanuel Atamo

Wollo University

Semere Reda

Wollo University

\section{Research}

Keywords: Malaria trend, distribution, Plasmodium falciparum, Plasmodium vivax, Ethiopia

Posted Date: June 22nd, 2021

DOl: https://doi.org/10.21203/rs.3.rs-624263/v1

License: (c) (i) This work is licensed under a Creative Commons Attribution 4.0 International License.

Read Full License 


\section{Abstract}

Background: Malaria is still the leading cause of morbidity and mortality in developing countries including Ethiopia. Ethiopia is planned to minimize forty percent of malaria incidence at the end of 2020 by applying different prevention and control method. There is limited information about trend of malaria in the study area. Therefore, this study was designed to address this gap.

Methods: Institutional based retrospective study was conducted from to determine a six-year trend analysis of malaria prevalence in the Bati district. All malaria cases were carefully reviewed by trained laboratory technologists from the laboratory record books of Bati hospital and health center. The data was entered in to excel 2013 and descriptive statistics were used to determine frequencies and percentages of malaria cases, trends of malaria transmission in terms of years and seasonal distribution.

Result: A total of 84,269 and 22,185 malaria suspected patients were requested for blood films and Rapid diagnostic tests (RDT) respectively. Of this, 12,032 (11.3\%) malaria cases were microscopically confirmed. Plasmodium falciparum were the most dominant parasite detected, which accounted for 57.6 $\%$. The highest peak of malaria cases was reported during the summer season. The majority of the cases $(57.2 \%)$ were reported among the $>15$ years age group

Conclusion: Malaria is still a major public health problem in the study area. In order to decrease the number of malaria cases further, government, all healthcare workers, and community should strengthen and scale up malaria prevention and control strategies in the study area.

\section{Introduction}

Malaria is characterized as a significant public health problem and poses high mortality and morbidity globally [1, 2]. It is caused by Plasmodium parasites [3]. In 2018, there were more than 228 million malaria cases were reported and 405,000 deaths. Of these deaths, $67 \%$ (272 000) were under-five children globally. This indicates that the burden of malaria is more overwhelming in children and pregnant women because of their weaker immune system. According to the world health organization, around 213000 (93\%) malaria cases and 380, 000 deaths were reported in Africa followed by South-East Asia Region with 3.4\% [4]. Beyond to morbidity and mortality, malaria make a significant impediment to social and economic developments [5]. Plasmodium falciparum and Plasmodium vivax are the most widely distributed and cause the best public health threat, particularly in developing countries [6]. In Ethiopia, an estimated 1.2 million cases are reported in 2018 [5] and 2,927,266 new malaria cases and 4782 deaths are reported in 2016. Malaria is the foremost cause of morbidity and mortality in Ethiopia, accounting for over five million cases and thousands of deaths annually [7]. This is primary due to $75 \%$ of the country is a malarious area and $68 \%$ of population living are life at risk of contracting malaria disease [8-10]. Moreover, the topography and climate condition of Ethiopia are more variable and unstable which make a favorable condition for malaria transmission [11]. 
To overcome the malaria morbidity and mortality, Ethiopian ministry of health is applying malaria prevention and control strategies such as early diagnosis and prompt treatment, selective vector control by indoor residual spraying (IRS), insecticide-treated mosquito nets (ITNs), and environmental management $[12,13]$. Furthermore, Ethiopia has just targeted malaria elimination nationwide at the end of 2030 aligned with the World Health Organization (WHO) Global Technical Strategy (GTS) through increasing the existing malaria prevention and control activities [14]. Ethiopia is applying different prevention and control method to minimize $40 \%$ of malaria incidence at the end of 2020 [15]. Analyzing the seasonal trends and prevalence of malaria from health facility is that the easiest and effective method and also it is input for expanding the prevention and control strategy and come up with new designing intervention method that might be assist malaria elimination at the end of 2030. Bati district is one of the hot and malarious area. The district was applying different malaria prevention and control interventions and there is a limited information on malaria transmissions at Bati district. Thus, this study aimed to assess the trend of malaria prevalence in the Bati district from 2015 to 2020.

\section{Methods}

\section{Study area}

The study was conducted in Bati district which is a special Oromia zone of Amhara national regional state, Northeastern Ethiopia. The data was collected from Bati hospital and health center. It is located at $11^{\circ} 11^{\prime} \mathrm{N}, 40^{\circ} 1^{\prime} \mathrm{E}$ and $1502 \mathrm{~m}$ above sea level (Figure 1). The mean annual rainfall is $155.1 \mathrm{~mm}$, and the maximum and minimum annual mean temperature of the town is $28^{\circ} \mathrm{C}$ and $8^{\circ} \mathrm{C}$, respectively.

\section{Study design}

Institutional based retrospective study was employed to determine a six-year (2015 - 2020) trend analysis of malaria prevalence in Bati district from October to December 2020.

\section{Data collection}

Six-year malaria cases data were collected from Bati Hospital and health center laboratory logbooks from October 2015 to December 2020. Total number of malaria cases diagnosed, the total number of blood film examined, species type such as $P$. falciparum, $P$. vivax, and age were collected by trained Medical laboratory technologists. In Bati hospital and health center, microscopy is used as a golden standard to confirm the presence of Plasmodium parasite and species identification.

The study hospital and health center strictly follow the standard operating procedures (SOPS) in all phases of quality control. All hospitals and health centers follow a standard operating procedure (SOP) in Ethiopia throughout the country for capillary blood sample collection, smear preparation, staining, and blood film examination for malaria parasite detection [16]. In these study areas, thick blood films were taken as positive if one or more malaria parasites have been observed; and, negative if no parasites were seen after examining 1000 white blood cells. Similarly, thin smears were considered positive for malaria if 
one or more malarial parasites were seen; and, negative if no asexual form of Plasmodium was observed in 200 high-power fields [17].

\section{Data analysis}

Data were entered into excel and descriptive statistics were used to analyze microscopically confirmed malaria cases in term of month and year, frequency and percentage of malaria cases, trend of malaria transmission. Malaria prevalence was computed by dividing the number of people who showed infection with Plasmodium species by the total number of people examined from the study population. Graphs and tables were used to depict the overall trend of malaria prevalence and malaria species distribution and season.

\section{Results}

\section{The trend of malaria prevalence in Bati district from 2015 to 2020}

Within the previous six years (2015-2020), a total of 106,454 malaria-suspected patients were diagnosed at both Bati hospital and the health center. Out of these, 84,269 and 22,185 malaria suspected patients were requested for blood films and RDT respectively. Of the total infected, 12,032 (99.6\%) malaria cases were confirmed by microscope with an average annual of 2,005. The number of malaria cases was reported though out the year with a different magnitude. The finding of this study showed that the number of confirmed malaria cases was steady increased from 2015 to 2016 . However, a slightly decreasing trend in the number of confirmed malaria cases was observed from 2016 to 2019 and steadily increased from 2019 to 2020 . The prevalence of malaria was fluctuating during the six years of study with minimum $(n=674)$ and maximum $(n=3,616)$ of annual malaria confirmed cases were reported by 2019 and 2016 years respectively (Figure 2). Thus, the total malaria prevalence over the six years in the Bati district was 11.3\%.

\section{Prevalence of malaria parasites among the age}

Of diagnosed Plasmodium species, $P$. falciparum was the dominant parasites species that accounted for $57.6 \%$. The overall prevalence of $P$. falciparum in the study area was $6.5 \%$, meanwhile $P$. vivax was (4.8\%). In the study area, malaria cases were observed in all age groups; however, the majority of the affected age group was $>15$ years old which accounted for (57.2\%) followed by the 5-14 age group (24.5\%). And also both $P$. falciparum and $P$. vivax were reported from all groups in each age category (Figure 3).

\section{Seasonal and monthly variation of malaria cases in Bati district}

Even though the prevalence of malaria has fluctuated through year, malaria cases were reported in all seasons. In this study, the majority of confirmed malaria cases was reported during summer (June, July and August) and the minimum was reported during autumn (Figure 5). At species level, the highest both $P$. falciparum and $P$. vivax were reported during summer while the smallest was autumn (Figure 4). 


\section{Malaria case distribution at Bati district from 2015 to 2020}

The present study showed that malaria cases distributed throughout the year. The highest malaria cases were reported during 2016 which was plasmodium falciparum (Table 1).

\section{Discussion}

This retrospective study was conducted with the aim of determining trend analysis of malaria in bati district. In this study, the total prevalence of malaria cases over six years was $11.3 \%$. This finding was noticeably lower than studies conducted in different parts of Ethiopia specifically woreta town (48\%) [18], Addi Arkay health center (36.1\%) [21], Abeshge, South-central part of Ethiopia (33.8\%) [22], Gondar, northwest part of Ethiopia (21.8\%) [20], and Metema hospital, northwest part of Ethiopia (17\%) [19]. On the other hand, it was higher than the studies conducted in Ataye town, North part of Ethiopia (8.4\%) [16], Bahirdar city (5\%) [24], and kombolcha town (7.5\%) [23]. The differences might be due to time variations of the studies, the difference of malaria prevention and control implementation activities, variations in geographical locations, and differences in insecticide application in the areas.

According to this study, the number of confirmed malaria cases was steady increased from 2015 to 2016 which indicates that the area needs attention to intensify the existing interventions to enhance malaria elimination efforts. However, a slightly decreasing trend in the number of confirmed malaria cases was observed from 2016 to 2019. This reduction of malaria cases over three years was due to the Bati health district was consistently implemented malaria prevention and control including distributes Insecticide Treated Net (ITN), create health awareness about malaria prevention and control to the community. This reduction is also due to effective malaria control and prevention strategies which are being implemented by the Federal Ministry of Health in the whole malaria areas by emphasizing to reduce malaria cases to zero.

Regarding the distribution of plasmodium species in the study area, Plasmodium falciparum was the dominant species which accounted for $57.6 \%$ followed by $P$. viva (42.4\%). This finding was similar to the retrospective studies conducted in Raya Azebo which accounted for Plasmodium falciparum (56.9\%) and P. viva $43.1 \%$ [26] and around Gilgel Gibe Hydroelectric Dam (GGHD), which accounts for Plasmodium falciparum (54.6\%) and Plasmodium vivax (41.6\%) [1]. As compared to the studies, this finding was consistence with studies conducted in different part of Ethiopia such as Kola Diba, North Gondar [28]; Raya Azebo Northern Ethiopia [26]; Butajira, Southern Ethiopia [2]; Jimma, Southwest Ethiopia [27]. On other hand, the prevalence of $\mathrm{p}$. falciparum was slightly less than a result reported from a retrospective study reported in Kola Diba health center (75\%) [28]. This is mainly due to the implementation of malaria prevention and control activities which might differ from one area to another show that the interventions in our study area might have been stronger.

The numbers of confirmed malaria cases were varied from season to season and also year to year. The prevalence and magnitude of malaria transmission are mainly determined by environmental, climatic, seasonal factors and behavioral factors. In this study, the highest malaria cases were reported during the 
summer season (47.2\%). This finding was in agreement with the retrospective studies conducted in Kombolcha town [23]; Ataye town [16]; Northwest Gondar [20]. This might be due to the similarity of climate conditions and altitude differences. This is also true as explained by the federal democratic republic of Ethiopia's ministry of health's national strategic plan for malaria prevention there two peak malaria transmission seasons are from September to December and following the rainy season from June to September. However, in this study, malaria cases were high in the summer season. This is maybe due to the relapsing behavior of the malaria parasite and irregular rainfall in the area [9].

According to this study, malaria was detected in all age groups. In the current study, the highest prevalence of malaria was observed among $\geq 15$ age groups (57.2\%) followed by 5 to 15 age groups (24.5\%) and under-five children (18.3\%). This finding was consistence with studies conducted in different parts of Ethiopia for instance Raya Azebo [26]; Addi Arkay health center [21]; Ataye Northshoa [16]; and Abeshge town [22]; Northwest Gondar [20]. This might be because productive age groups often engaged in farm activities in the fields.

\section{Conclusion}

Plasmodium falciparum was dominant and followed by Plasmodium vivax. The overall trends of total confirmed malaria cases were decreased in the past 6 years (2015-2020) with exception slightly increased in cases from 2015 to 2016. In general, malaria is a major public health problem in the Bati district. Therefore, the government, all healthcare works, and communities should strengthen and scale up malaria prevention and control strategies in the study area.

\section{Limitation of the study}

This study was assessed the trend analysis of malaria prevalence in Bati district. In this study, secondary data were used to analyze the trends of malaria, which could be underestimate or overestimate the prevalence of malaria in the study area since the data was not collected from the community. The registered data was miss some important variables such as sex and number of death, therefore difficult to measure the morbidity of malaria in the study area. Further study that focused on community based trend analysis of malaria is highly encouraged to provide more representative evidence for Bati district.

\section{Abbreviations}

IRS: Indoor Residual Spray; BF: Blood Film; ITNs: Insecticide-Treated Nets; RDT: Rapid Diagnostic Tests; SOPs: Standard Operating Procedures; WHO: World Health Organization

\section{Declarations}

\section{Ethics approval and consent to participate}


Ethical clearance was obtained from the ethical review committee of Wollo University. After discussing the purpose and method of the study, verbal consent was obtained from the heads of health institutions before the data extraction.

\section{Consent for publication}

Not applicable

\section{Availability of data and materials}

The datasets used and/or analyzed during the current study are available in the hands of the corresponding authors on reasonable request.

\section{Competing interests}

The authors declare that they have no competing interests

\section{Funding}

No fund was received for this research

\section{Authors' contributions}

$\mathrm{CD}, \mathrm{EK}, \mathrm{AA}$ and $\mathrm{SM}$ involved in proposal writing, methodology development and review the document and analyze the data and manuscript preparation

\section{Acknowledgments}

We would like to acknowledge Wollo University, College of Medicine and Health Science to write the support letter and Bati health center and Hospital manager for their cooperation during data extraction

\section{References}

1. Yewhalaw D, Legesse W, Van Bortel W, Gebre-Selassie S, Kloos H, Duchateau L, et al. Malaria and water resource development: The case of Gilgel-Gibe hydroelectric dam in Ethiopia. Malar J. 2009;8(1):1-10.

2. Tesfaye S, Belyhun Y, Teklu T, Mengesha T, Petros B. Malaria prevalence pattern observed in the highland fringe of Butajira, Southern Ethiopia: A longitudinal study from parasitological and entomological survey. Malar J. 2011;10:1-9.

3. Martens P, Hall L. Malaria on the move: Human population movement and malaria transmission. Emerg Infect Dis. 2000;6(2):103-9.

4. WHO. World malaria report 2019. 2019.

5. CDC. U. S. Presedent malaria intitiative ethiopia malaria Operational Plan FY 2020. 2020. 
6. UNICEF/WHO. Achieving the malaria MDG target: reversing the incidence of malaria 2000-2015. WHO Glob Malar Program.

7. Girum T, Shumbej T, Shewangizaw M. Burden of malaria in Ethiopia, 2000-2016: Findings from the Global Health Estimates 2016. Trop Dis Travel Med Vaccines. 2019;5(1):5-11.

8. CDC U. President ' S Malaria Initiative Malaria Operational Plan (Mop) Ethiopia Fy2012. Malar J. 2009;2009, 8:29.

9. FMOH. National Strategic Plan for Malaria Prevention Control and Elimination in Ethiopia 20112015. 2010;2015(August 2010):76.

10. Woyessa A, Deressa W, Ali A, Lindtjørn B. Prevalence of malaria infection in Butajira area, southcentral Ethiopia. Malar J. 2012;11(1):84.

11. Petros B, Geshere G. Trend of Malaria Prevalence in Ilu Galan, Bako Tibe, and Danno Districts of West Shoa Zone, OromiyaRegion, Ethiopia. 2014.

12. Gari T, Lindtjørn B. Reshaping the vector control strategy for malaria elimination in Ethiopia in the context of current evidence and new tools: Opportunities and challenges 11 Medical and Health Sciences 1108 Medical Microbiology 11 Medical and Health Sciences 1117 Public He. Malar J. 2018;17(1):1-8. doi.org/10.1186/s12936-018-2607-8.

13. Taffese HS, Hemming-Schroeder E, Koepfli C, Tesfaye G, Lee MC, Kazura J, et al. Malaria epidemiology and interventions in Ethiopia from 2001 to 2016. Infect Dis Poverty. 2018;7(1):1-9.

14. FDRE. Federal Democratic Republic of Ethiopia Ministry of Health. National Malaria Elimination Roadmap Addis Ababa. 2016;6(1):1-32.

15. WHO. World malaria report 2018. Geneva: World Health Organization; 2018. https://www.who.int/malaria/publications/ world-malaria-report-2018/en/. 2018.

16. Feleke DG, Gebretsadik D, Gebreweld A. Analysis of the trend of malaria prevalence in Ataye, North Shoa, Ethiopia between 2013 and 2017. Malar J. 2018;17(1):1-6. doi.org/10.1186/s12936-0182474-3.

17. Moges B, Amare B, Belyhun Y, Tekeste Z, Gizachew M, Workineh M, et al. Comparison of CareStart HRP2/pLDH COMBO rapid malaria test with light microscopy in north-west Ethiopia. Malar J. 2012;11:1-6.

18. Alelign A, Tekeste Z, Petros B. Prevalence of malaria in Woreta town, Amhara region, Northwest Ethiopia over eight years. BMC Public Health. 2018;18(1):1-6.

19. Ferede G, Worku A, Getaneh A, Ahmed A, Haile T, Abdu Y, et al. Prevalence of malaria from blood smears examination: A seven-year retrospective study from Metema Hospital, Northwest Ethiopia. Malar Res Treat. 2013;2013:0-2.

20. Addisu A, Tegegne Y, Mihiret Y, Setegn A, Zeleke AJ. A 7-Year Trend of Malaria at Primary Health Facilities in Northwest Ethiopia. J Parasitol Res. 2020;2020.

21. Tesfa H, Bayih AG, Zeleke AJ. A 17-year trend analysis of malaria at Adi Arkay, north Gondar zone, Northwest Ethiopia. Malar J. 2018;17(1):1-6. doi.org/10.1186/s12936-018-2310-9. 
22. Yimer F, Animut A, Erko B, Mamo H. Past five-year trend, current prevalence and household knowledge, attitude and practice of malaria in Abeshge, south-central Ethiopia. Malar J. 2015;14(1):1-11. doi.org/10.1186/s12936-015-0749-5.

23. Gebretsadik D, Feleke DG, Fiseha M. Eight-year trend analysis of malaria prevalence in Kombolcha, South Wollo, north-central Ethiopia: A retrospective study. Parasites Vectors. 2018;11(1):1-6.

24. Yimer M, Hailu T, Mulu W, Abera B, Ayalew W. A 5 year trend analysis of malaria prevalence with in the catchment areas of Felegehiwot referral Hospital, Bahir Dar city, northwest-Ethiopia: A retrospective study. BMC Res Notes. 2017;10(1):4-7.

25. Tesfay K, Yohannes M, Bayisa S. Trend analysis of malaria prevalence in Raya Azebo district, Northern Ethiopia: A retrospective study. BMC Res Notes. 2018;11(1):1-5. doi.org/10.1186/s13104018-4003-4.

26. Sena LD, Deressa WA, Ali AA. Analysis of trend of malaria prevalence in south-west Ethiopia: A retrospective comparative study. Malar J. 2014;13(1):1-9.

27. Alemu A, Tsegaye W, Golassa L, Abebe G. Urban malaria and associated risk factors in Jimma town, south-west Ethiopia. Malar J. 2011;10:1-10.

28. Abebe alemu. dagnachew, muluye;mikrie, mihret; meaza, adugna; melkamu gebeyaw. Ten year trend analysis of malaria prevalence in Kola Diba, North Gondar, Northwest Ethiopia. parasite vectors. 2012;9(6):277-81.

\section{Tables}

Table 1: Malaria case distribution at Bati district from 2015 to 2020

\begin{tabular}{|llllll|}
\hline Years & $\begin{array}{l}\text { Total numbers blood } \\
\text { film examined }\end{array}$ & $\begin{array}{l}\text { Total numbers of RDT } \\
\text { examined }\end{array}$ & & $\begin{array}{l}\text { Total } \\
\text { confirmed } \\
\text { cases }\end{array}$ & \multicolumn{2}{c|}{$\begin{array}{l}\text { Plasmodium } \\
\text { species }\end{array}$} \\
\cline { 6 - 7 } & & 2662 & & $\begin{array}{l}\text { p. } \\
\text { falciparum }\end{array}$ & $\begin{array}{c}\text { p. } \\
\text { vivax }\end{array}$ \\
\hline 2015 & 12338 & 3883 & 2220 & 1287 & 933 \\
\hline 2016 & 18427 & 4720 & 3616 & 2042 & 1574 \\
\hline 2017 & 17800 & 4923 & 3023 & 1379 & 1644 \\
\hline 2018 & 18324 & 34 & 1588 & 855 & 733 \\
\hline 2019 & 13264 & 5963 & 674 & 532 & 142 \\
\hline 2020 & 4116 & 22185 & 911 & 840 & 71 \\
\hline Total & $\mathbf{8 4 2 6 9}$ & & 12032 & 6935 & 5097 \\
\hline
\end{tabular}

\section{Figures}




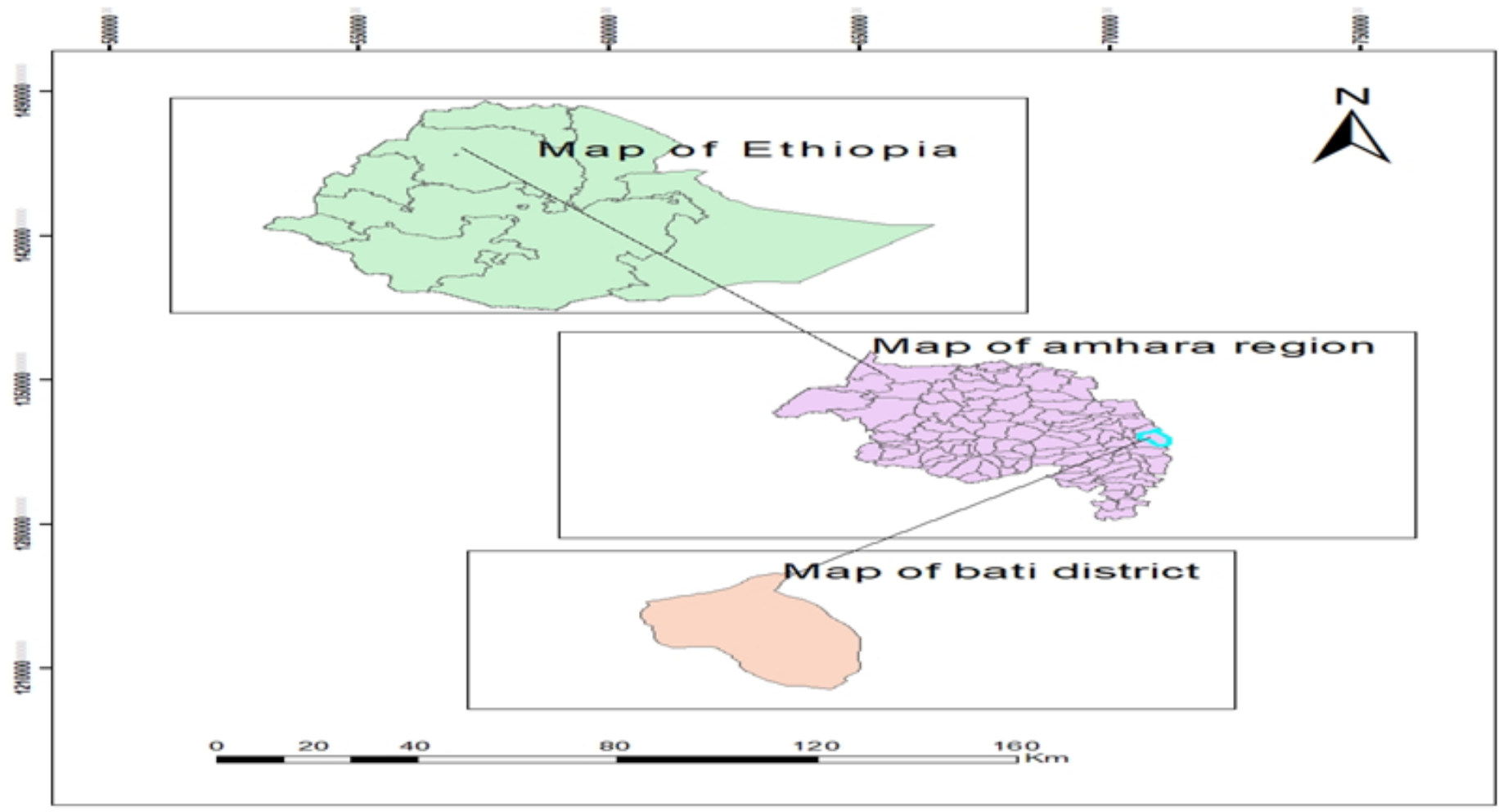

\section{Figure 1}

Map of study area Note: The designations employed and the presentation of the material on this map do not imply the expression of any opinion whatsoever on the part of Research Square concerning the legal status of any country, territory, city or area or of its authorities, or concerning the delimitation of its frontiers or boundaries. This map has been provided by the authors.

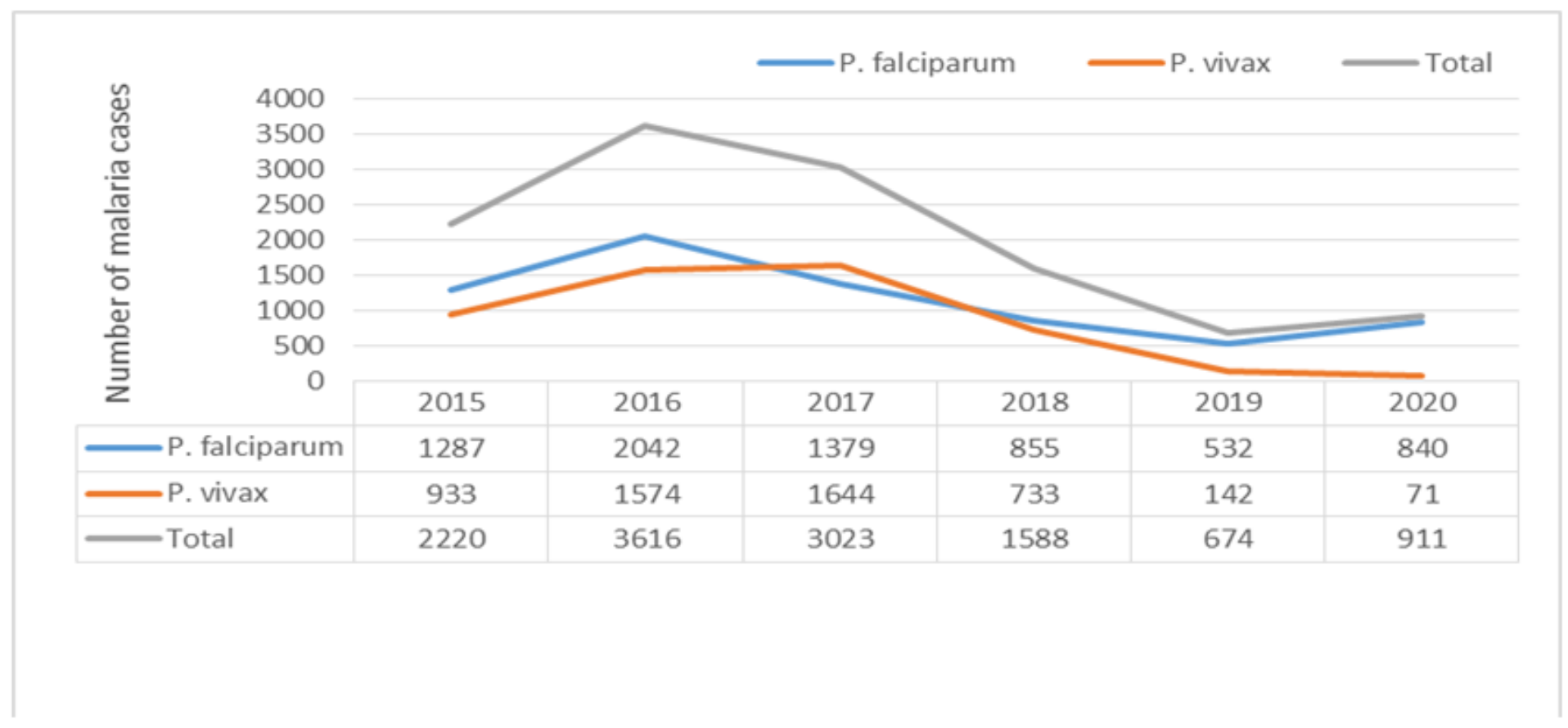

Figure 2 
Annually prevalence of malaria cases at bati district, Ethiopia from 2015 to 2020

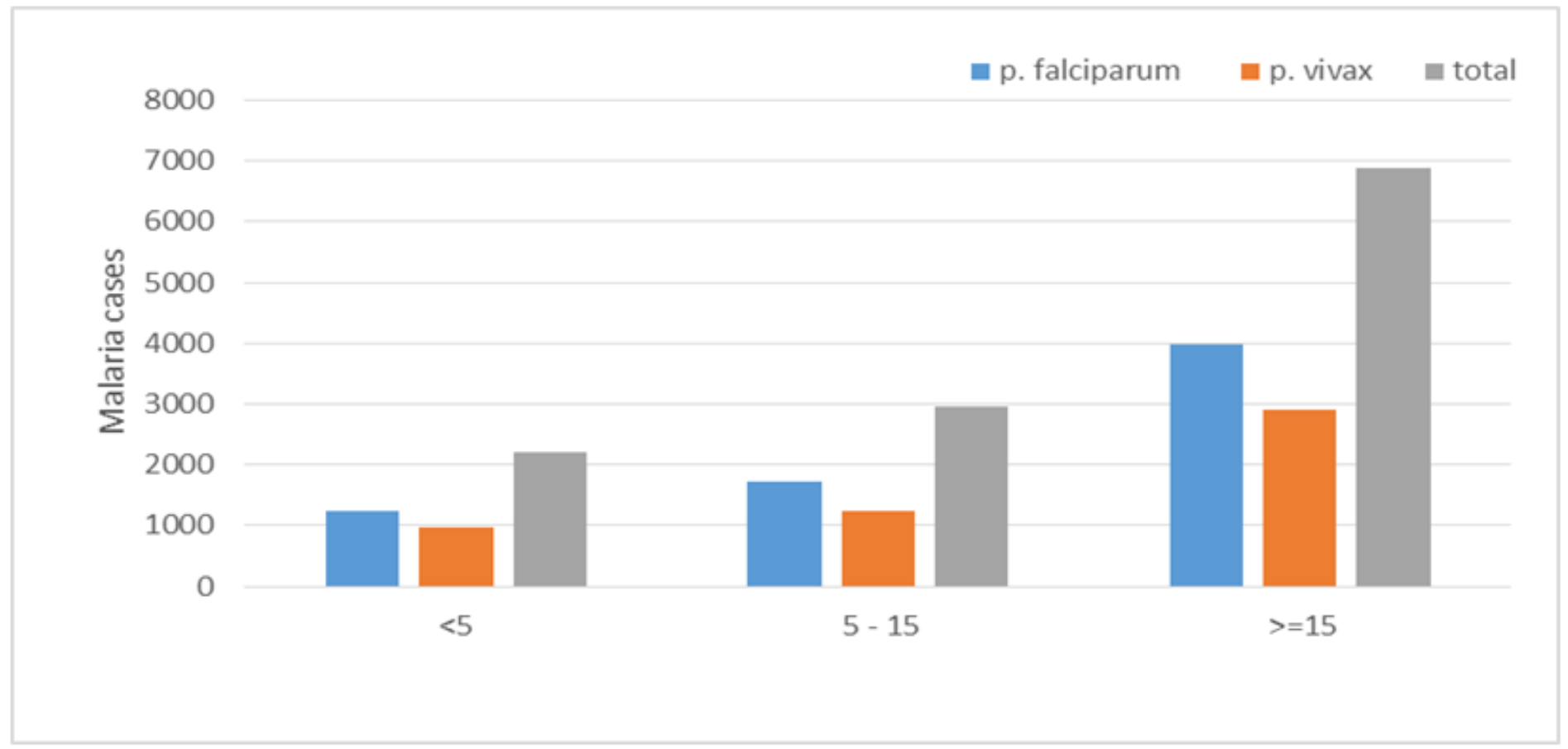

\section{Figure 3}

Six year trend analysis of malaria species by age at Bati district from 2015 to 2020

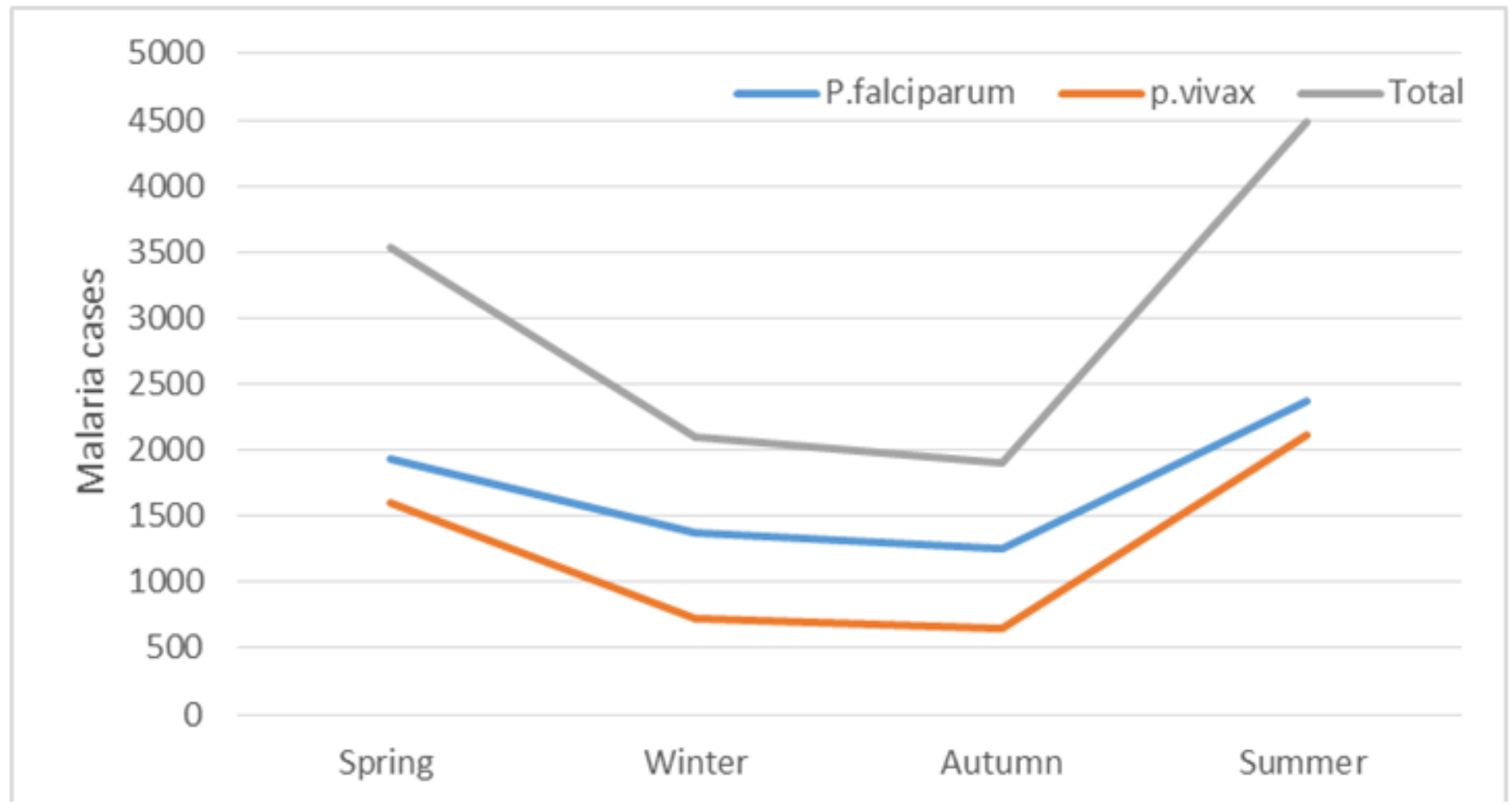

Figure 4 
Six year trend analysis of plasmodium species by season at Bati district from 2015 to 2020

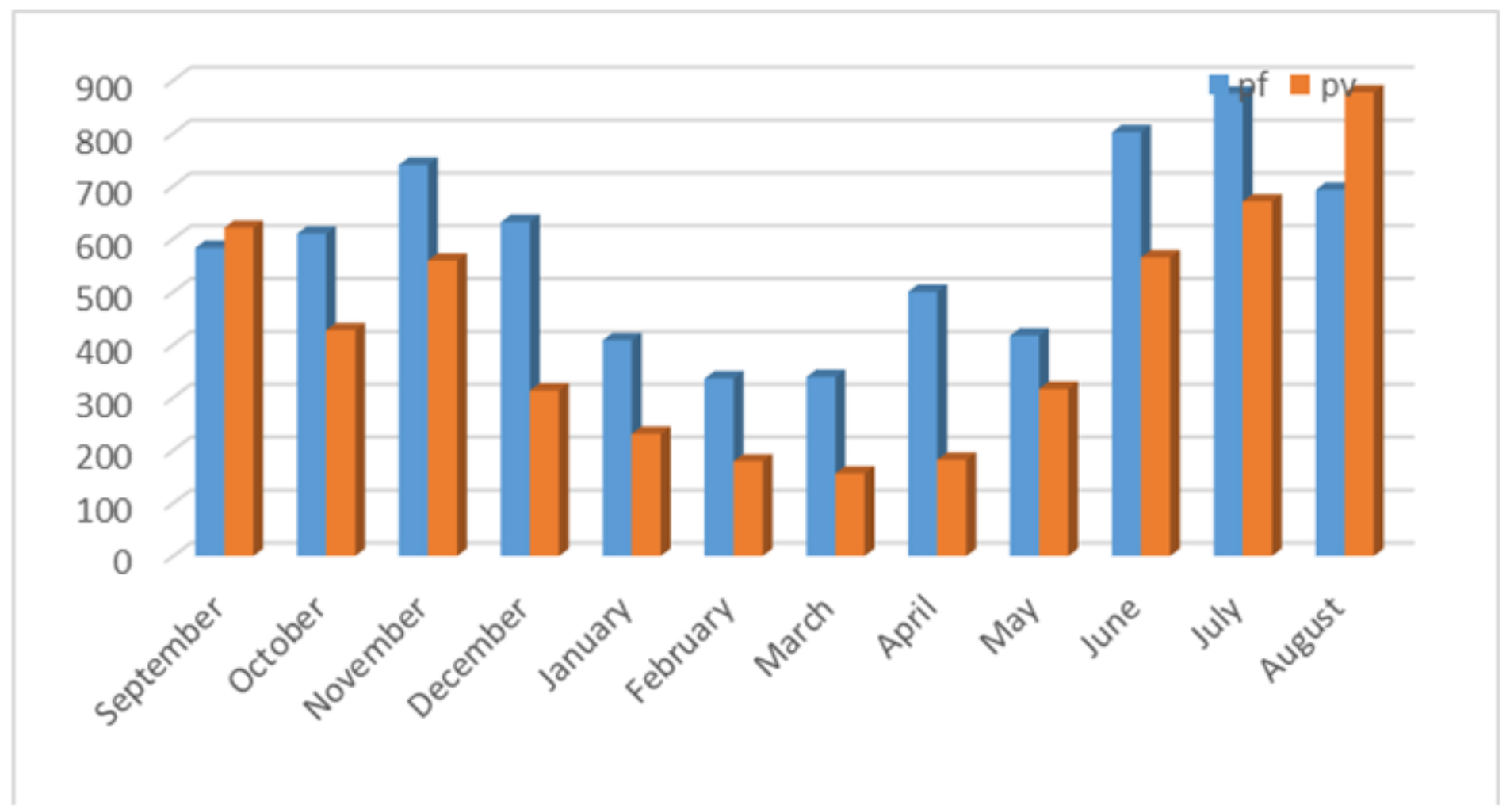

Figure 5

Six year trend analysis of plasmodium species by months at Bati district from 2015 to 2020 